\title{
A miniature microdrive for recording auditory evoked potentials from awake anurans
}

\author{
Haitham S. Mohammed ${ }^{1}$, Nasr M. Radwan' ${ }^{2}$, Wolfgang Walkowiak ${ }^{3}$ and Anwar A. Elsayed ${ }^{1}$ \\ ${ }^{1}$ Biophysics Department, Faculty of Science, Cairo University, Giza, Egypt \\ ${ }^{2}$ Zoology Department, Faculty of Science, Cairo University, Giza, Egypt \\ ${ }^{3}$ Zoological Institute, University of Cologne, Cologne, Germany
}

\begin{abstract}
Electrical activity recording from the brains of awake animals is a corner stone in the study of the neurophysiological basis of behavior. To meet this need, a microelectrode driver suitable for the animal of interest has to be developed. In the present study a miniature microdrive was developed specifically for the leopard toad, Bufo regularis, however, it can be used for other small animals. The microdrive was designed to meet the following requirements: small size, light weight, simple and easy way of attaching and removing, advancing and withdrawing of microelectrode in the animal brain without rotation, can be reused and made from inexpensive materials. To assess the performance of the developed microdrive, we recorded auditory evoked potentials from different auditory centers in the toad's brain. The potentials were obtained from mesencephalic, diencephalic and telencephalic auditory sensitive areas in response to simple and complex acoustic stimuli. The synthetic acoustical tones introduced to the toad were carrying the dominant frequencies of their mating calls.
\end{abstract}

Key words: Anuran - Brain - Microdrive - Auditory - Acoustic stimulus

\section{Introduction}

A major aim of neuroscience is to understand the relationship between brain activity and behaviour. Investigators have developed techniques to record activity within the brain of behaving animals (Korshunov 1995; Kralik et al. 2001; Battaglia et al. 2009; Galashan et al. 2011). These techniques usually involve electrodes attached to a device, in a manner that allows for their gradual advancement into the brain structure of interest. Such a device (microdrive) should meet several requirements; small size and weight, precise advancement and withdrawal, stability over time, simple installation and low cost.

Sensory evoked potentials can be used to test the suitability of a microdrive, because they occur in a defined period of time (shortly after a stimulus) and can therefore be averaged easily. Moreover, their general waveform patterns are usually well documented (Carey and Zelick 1993; Feng et al. 2006). A sensory evoked response may be defined as a local signal generated by integration of membrane currents in response

Correspondence to: Haitham S. Mohammed, Biophysics Department, Faculty of Science, Cairo University, Giza, Egypt

E-mail: haitham_sharaf@yahoo.com to the stimulation of a peripheral sense organ or sensory nerve. Evoked potentials appear at certain time interval after the stimulus (i.e. latency) and usually in a particular wave shape pattern. Depending on the type of electrode used the evoked response represents the combined activity of some to many neurons. Because of the longer time constants, afferent activity processed in the dendrites contributes more strongly to local field potentials than spike activity.

Auditory evoked potentials (AEP) in animals have been of interest to gain insight into the auditory pathway and auditory neurophysiology. For example, Feng et al. (2006) have used AEP from the midbrain auditory center in the frog central nervous system to validate the ultrasonic sensitivity of a certain anurans species (A. tormotus).

Several researchers have adopted different strategies for developing microdrives that are suitable to their work (McHughet al. 1996; Yu and Margoliash 1996; Yamamoto and Wilson 2008). Experiments are often carried out with small animals such as rats, mice, or birds. Some of the developed microdrives are relatively heavy, often exceeding $10 \%$ of the animal's body weight (e.g. $3.5 \mathrm{~g}$ for the device described by McHugh et al. (1996), or about $8 \mathrm{~g}$ for the device used by Yamamoto and Wilson (2008)). The weight of the electrode 
drive limits the range of feasible behavioral tasks to very basic ones, such as spatial exploration and foraging.

Anurans are especially attractive as research subjects because their auditory system allows integrative studies of neural, behavioural, and evolutionary biology in a way offered by very few other auditory systems. The central auditory system of anuran has major auditory nuclei (torus semicircularis, auditory thalamus and telencepahlic medial pallium) concerned with sound processing and analysis. The torus semicircularis in the midbrain which is homologous to the inferior colliculus in the mammalian brain is a major center for processing of acoustic signals (Hall 1994; Walkowiak and Luksch 1994). The main ascending connections from the torus terminate in the central thalamic nucleus but several other nuclei in this region receive inputs from the central thalamic nucleus and directly from the tours as well (Neary 1988), so that auditory sensitivity is widespread in the diencephalon. Although a homologue of the auditory cortex does not exist in the anuran telencephalon, some telencephalic areas receive connections from auditory nuclei in the diencephalon and/or directly from the torus (Neary 1988). Therefore, auditory evoked potentials can be recorded from numerous locations in the brain.

The present study aimed at designing and constructing a miniature microdrive suitable to be mounted on the head of small animal like the Leopard toad (Bufo regularis). Furthermore, we report recording of auditory evoked potentials from telencephalic, diencephalic, and mesencephalic auditory centers in the toad's brain.

\section{Materials and Methods}

\section{Experimental animals}

The experimental animals used in the present study were Egyptian leopard toads (Bufo regularis). The animals were housed for 1-2 weeks to get adapted on the laboratory environment. The animals had an average snout-vent length of $6-8 \mathrm{~cm}$ and were purchased from commercial suppliers in Egypt (Wadi Al-Nil Co., Cairo, Egypt). They were housed in groups of 6 to 8 animals in glass terraria $(60 \times 30$ $\times 30 \mathrm{~cm}^{3}$ ) for $1-2$ weeks prior to experiments. The terraria were equipped with suitable amounts of mud, water and stones for the toads to hide. The temperature was maintained at $20-25^{\circ} \mathrm{C}$, and a light/dark cycle (of $12 \mathrm{~h} / 12 \mathrm{~h}$ with lights on at 6:00 a.m.). Toads were fed on mealworms, which provided twice a week. The electrophysiological recordings were obtained from 10 toads (Snout to tail dimension was $10-13 \mathrm{~cm}$ ).

\section{Design and construction of the microdrive}

The microdrive was assembled from 7 parts, as shown in Fig. 1: driving screw, scalar, microdrive body, microelectrode holder, nut, base and positioning screw. The microdrive body is L-shaped plastic piece of $25 \mathrm{~mm}$ length, $3 \mathrm{~mm}$ thickness and $6 \mathrm{~mm}$ width. A $20 \mathrm{~mm}$ long and $1 \mathrm{~mm}$ wide opening

A

B
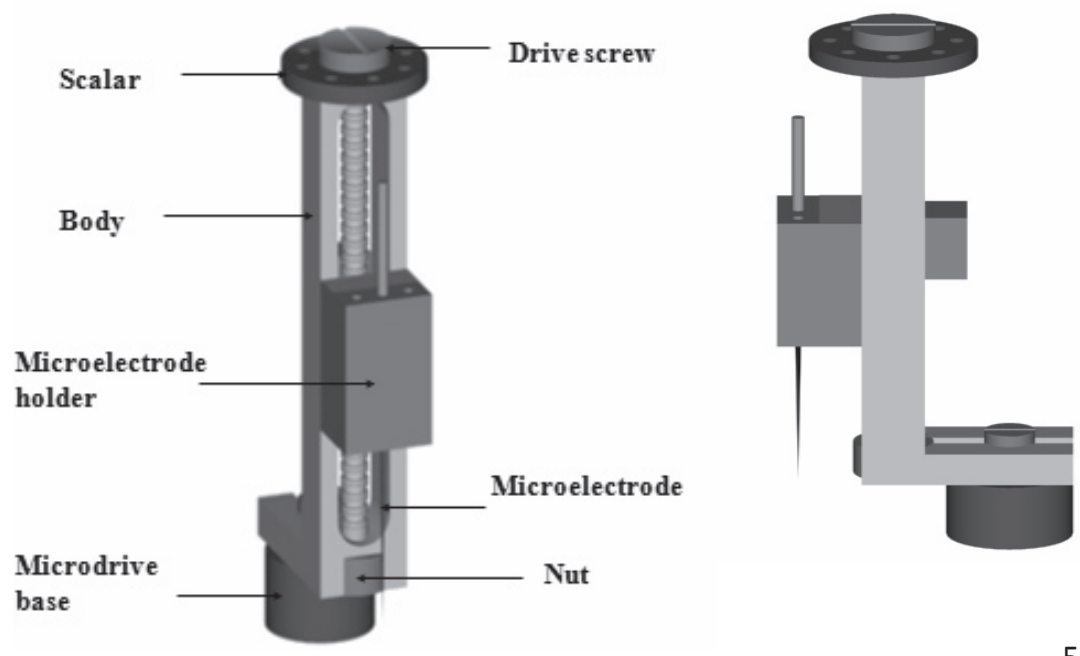

$5 \mathrm{~mm}$

Figure 1. A. Schematic diagram depicting the different parts of the microdrive. B. Side view of the microdrive. 
was made in the anterior part of the microdrive. Two holes drilled in the upper and lower ends with a diameter of $1 \mathrm{~mm}$. A sleeve protruding $5 \mathrm{~mm}$ from the end of this part was made at the posterior part of the microdrive body.

The microelectrode holder was constructed as a separate part and made of plastic. The anterior part of the holder was $7 \mathrm{~mm}$ long, $4 \mathrm{~mm}$ thick and $6 \mathrm{~mm}$ wide. The posterior part was $5 \mathrm{~mm}$ long, $2 \mathrm{~mm}$ thick and $3 \mathrm{~mm}$ wide. A hole was drilled in the anterior part with $\sim 0.5 \mathrm{~mm}$ in diameter. Another hole $\sim 1 \mathrm{~mm}$ in diameter was drilled in the posterior part of the microelectrode holder.The driving screw was constructed (home made) with $28 \mathrm{~mm}$ length and had 4 turns $/ \mathrm{mm}$. The scalar is a circular sheet of plastic, which has a diameter of $7 \mathrm{~mm}$, and 8 holes were drilled at equal distancesin the scalar nearby the outer border. The nut has inner diameter of $1 \mathrm{~mm}$ and a thickness of $1 \mathrm{~mm}$. The microdrive base has a cylindrical shape $4 \mathrm{~mm}$ high and a circular diameter of $5 \mathrm{~mm}$. A hole was drilled through the base to receive a small screw $4 \mathrm{~mm}$ long. By turning the driver (adjusting) screw clockwise the microelectrode moves ventrally without any rotation, as there is no direct connection between the screw and the microelectrode, but the movement is transformed through the microelectrode holder. Turning the screw anticlockwise moves the microelectrode dorsally. This possibility enables multiple penetrations of the microelectrode into the brain tissue during the same experiment, and recording of the electrical activities from different brain depths. One full turn of the driver screw advances the microelectrode by $250 \mu \mathrm{m}$. The 8 equally distant holes at the microdrive scalar ensure that, the driver screw can be turned as little as 1/8 turn and advance the microelectrode by about $31 \mu \mathrm{m}$. The total distance that the microelectrode can travel is about $15 \mathrm{~mm}$ (which enables the microelectrode to reach nuclei at any depth inside the brain) and the weight of the whole assembly is $1.5 \mathrm{~g}$. The microdrive assembly (base and shaft) occupy only the third of the area available over the animal head. The electrical connection was made through a miniaturized female pin (FHC, Bowdoinham, USA) which is connected to the microelectrode pin only during the recording procedure.

\section{Animal surgery}

The experimental animal was anaesthetized by immersion in $0.2 \%$ tricainemethanesulfonate (MS 222, Sigma-Aldrich) for approximately 10 minutes. Then, the animal was wrapped in moist tissue to maintain cutaneous respiration. The dorsal skin was incised near the nasal openings to the insertion of the neck muscles. An opening of $5 \mathrm{~mm}$ in diameters was made in the exposed bone of the animal's skullby aid of a drill of $1 \mathrm{~mm}$ tip diameter (Proxxon, Germany). Care was taken to prevent any bleeding from the two main blood vessels running at both sides of the toad's head. The dura mater was then cut and retracted by aid of the fine scissor and forceps. A very small cut in pia mater was made allowing the electrode to enter the brain tissue without opposition. The assembled microdrive loaded with the microelectrode is then fixed over the animal head via its permanently cemented base. The fixed base ensured that the microelectrode doesn't move during animal movement and granted the repositioning of the microelectrode within the same area of recording between experiments. By turning the drive screw, the microelectrode can be lowered into the brain. After advancing the microelectrode into the brain tissue, one drop of paraffin oil poured over the opened area to keep the exposed brain from drying out. Pin electrode was inserted under the animal's skin in nearby inactive area acting as an indifferent electrode.

\section{Experimental setup and recording procedures}

Experiments were made in a soundproof, reflectiondamped chamber $\left(190 \times 220 \times 190 \mathrm{~cm}^{3}\right)$. The animal was placed in an acoustically-transparent Faraday cage $(30 \times$ $\left.30 \times 30 \mathrm{~cm}^{3}\right)$. The sound stimuli were delivered through a loudspeaker placed $80 \mathrm{~cm}$ away from the Faraday cage. The acoustic stimuli were synthesized and back played using a Tucker Davis Technologies (TDT) system. The acoustic stimuli used in the present study were simple $(600 \mathrm{~Hz})$ and complex tones $(600+1500 \mathrm{~Hz})$, which have frequencies matching the animal's mating call (see Akef and Schneider (1990) for mating call parameters). The sound pressure level (SPL) was estimated by a sound level meter (Brüel and Kjaer 2203, Germany). All the acoustic stimuli were back played at SPL of $70 \mathrm{~dB}$.

Sensory evoked potentials were picked up by using a tungsten microelectrode $(1 \mathrm{M} \Omega, 5 \mu \mathrm{m})$, amplified $\left(\times 10^{4}\right)$ by a battery-powered amplifier (DAM 70, WPI, USA), digitized by an analog/digital converter (Microstar laboratories Inc., USA), displayed on the screen, and saved on the computer's hard disk for offline analysis. Evoked potentials and multiunit activities were picked up from different auditory nuclei, in response to the back played acoustic stimuli, by the same microelectrode. However, they were discriminated by digital band-pass filtration at $1-300 \mathrm{~Hz}$ and $100-3000 \mathrm{~Hz}$, respectively. Latency and duration of these neural activities were determined in the midbrain (torus semicircularis), diencephalic (dorsal thalamus) and telencephalic (medial palium) auditory nuclei.

\section{Histological procedures}

Tissue sections were made after the end of each experiment to verify the recording site, by using the Nissl-staining method. A lesion was made by passing $0.5 \mu \mathrm{A}$ current through the recording electrode, which was subsequently removed. The 
toads were lethally anaesthetized by immersion in $0.2 \% \mathrm{MS}$ 222, and perfused through the heart with a physiological saline solution. The toads were then decapitated and the head of the animal was incubated in Bouin fixative for 3-14 days. The fixed head was then rinsed in running tap water for 3-7 days. The brain was carefully dissected outas shown in Fig. 2, and incubated in $70 \%$ ethanol for 2-3 days. The brain was then transferred into $96 \%$ ethanol for $12 \mathrm{~h}$ and into $100 \%$ ethanol for 1-2 h. It was then treated with xylol for $2 \mathrm{~h}$ and again in a freshly prepared xylol for $3 \mathrm{~h}$. A solution of 1:1 from xylol and $70^{\circ} \mathrm{C}$ melted paraplast was prepared and the brain was kept for $2 \mathrm{~h}$ in this solution at $70^{\circ} \mathrm{C}$. The brain was left overnight in a pure paraplast solution. The brain embedded-paraplast was left at room temperature till it solidified. It was then sliced into $15 \mu \mathrm{m}$ sections via microtome.

\section{Results}

\section{Compatibility of the microdrive}

The neural recordings were executed in wake unanesthetized animals. The light weight of the designed microdrive (1.5 mg) enables the animals to behave without significant alterations in their normal behavior of walking, crawling and even jumping (Fig. 3).

\section{Histology}

Nissl stained sections revealed the track of the microelectrode within the brain tissue as shown in the Fig. 4 . This

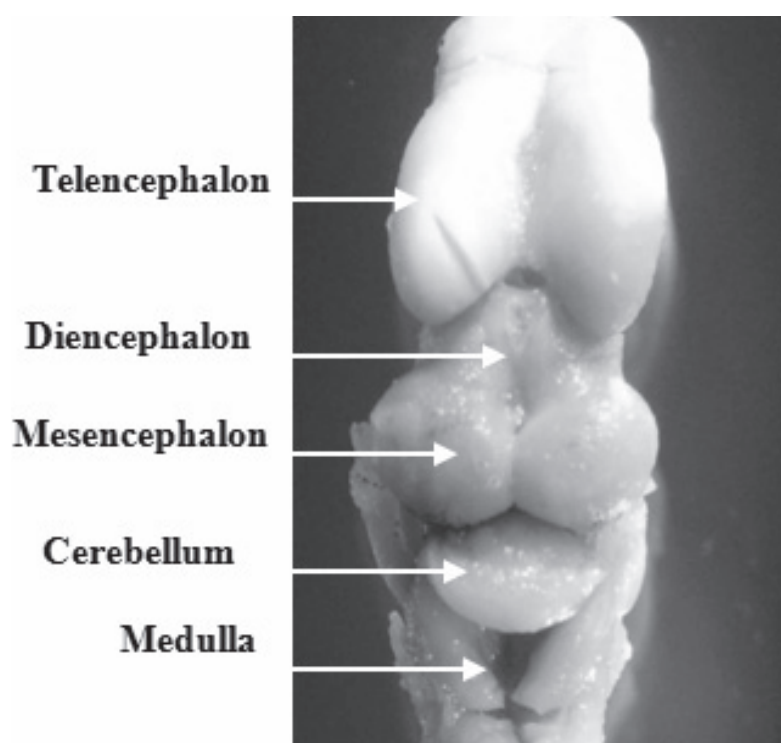

Figure 2. Dorsal view of the dissected-out brain of the Egyptian leopard toad (Bufo regularis).

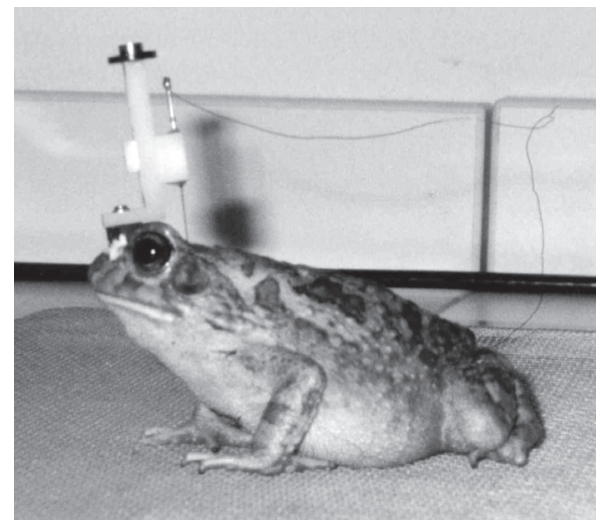

Figure 3. Photograph of the toad Bufo regularis carrying the microdrive.

procedure verifies the site of recording within the brain tissues after the end of the recording procedures.

\section{Electrical activity recorded from the midbrain}

As shown in Fig. 5 and Table 1, multiunit responses were obtained from the midbrain auditory nuclei (torus semicircularis) in the awake and freely moving toad (Bufo regularis) in response to the acoustic stimulus. The acoustic stimulus used was a simple tone of $600 \mathrm{~Hz}$ carrier frequency, rise/fall time of $10 \mathrm{~s}$ and duration of $500 \mathrm{~ms}$, which was played back at intervals of $2 \mathrm{~s}$. The depth of the microelectrode in the toad's brain ranged from 1000 to $1500 \mu \mathrm{m}$. The responses were of two types: A phasic response which appears only at the beginning of the acoustic stimulus $(0.3 \mathrm{mV})$ and a phasictonic response starting with a high amplitude $(0.6 \mathrm{mV})$

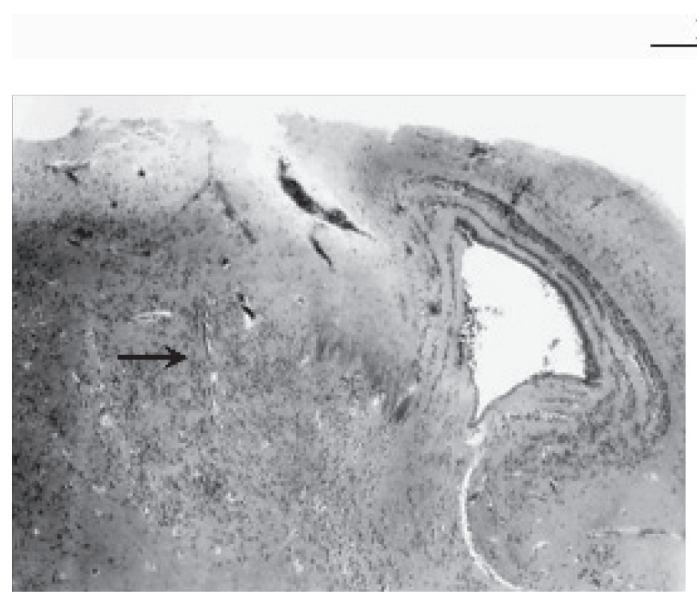

Figure 4. Photomicrograph of a $15 \mu \mathrm{m}$ Nissl-stained sagittal section showing the electrode track (arrow) in the thalamus of the toad Bufo regularis. 

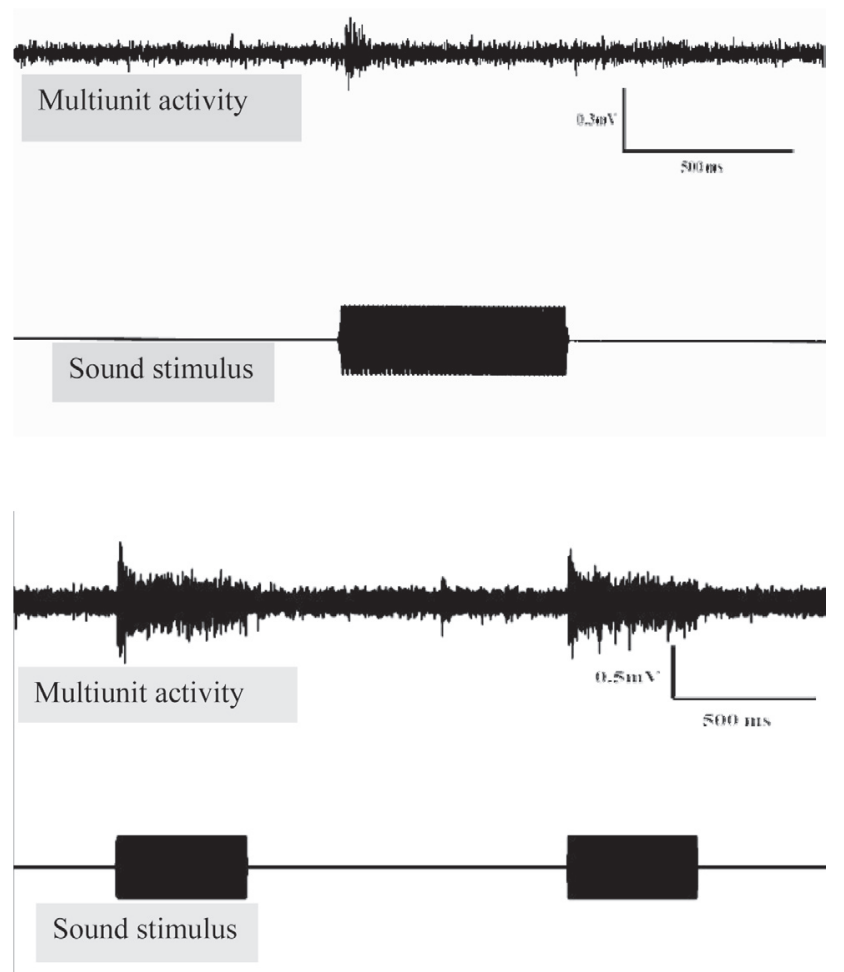

Figure 5. Phasic and phasic-tonic response in the midbrain of the toad Bufo regularis in response to a simple tone stimulus $(600 \mathrm{~Hz})$.

response followed by a sustained response during the whole period of the acoustic stimulus. The phasic responses were obtained in recording positions, which lay rostral to the recording positions of thephasic-tonic response in the torus semicircularis. The latencies of the phasic responses ranged from 11 to $18 \mathrm{~ms}$ and the duration of the responses from 21 to $40 \mathrm{~ms}$ (10 animals). The latency of the phasic-tonic responses ranged from 9 to $14 \mathrm{~ms}$ and the duration of the responses from 100 to $120 \mathrm{~ms}$ (10 animals).

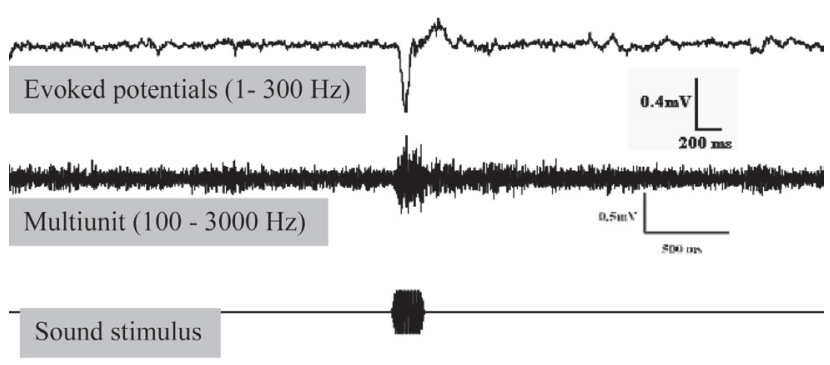

Figure 6. Evoked potentials and multiunit responses in the dorsal thalamus of the toad Bufo regularis in response to simple tone stimulus $(600 \mathrm{~Hz})$.

\section{Electrical activity recorded from the diencephalon}

As shown in Fig. 6 and Table 2, multiunit responses and evoked potentials were recorded in the central nucleus of the dorsal thalamus. The acoustic stimulus was a simple tone burst with carrier frequency of $600 \mathrm{~Hz}$, rise/fall time of $10 \mathrm{~ms}$ and duration of $100 \mathrm{~ms}$. The recording positions ranged from 250 to $500 \mu \mathrm{m}$. The evoked potential wave pattern was of bi-phasic type; it started with a large negative peak $(0.4 \mathrm{mV})$ followed by a small positive peak $(0.15 \mathrm{mV})$ and then returned to baseline. The multiunit responses had the same duration as the evoked potential, which ranged from 40 to $100 \mathrm{~ms}$. The latency of the responses in these auditory nuclei ranged from 17 to $22 \mathrm{~ms}$ (10 animals).

\section{Electrical activity recorded from the telencephalon}

As shown in Fig. 7, evoked potentials were recorded from the medial pallium, one of the auditory sensitive areas in the telencephalon of anurans. The recording positions ranged from $250-500 \mu \mathrm{m}$ from the brain's surface. The obtained signal was of bi-phasic pattern, started with positive peak $(0.65 \mathrm{mV})$ followed by negative one $(0.15 \mathrm{mV})$, then returned

Table 1. Latency and duration of the multiunit phasic and phasic-tonic responses in the torus semicricularis (midbrain) of the toad Bufo regularis $(n=10)$

\begin{tabular}{lcccc}
\hline Response & Latency $(\mathrm{ms})$ & Duration $(\mathrm{ms})$ & Stimulus $(\mathrm{Hz})$ & Stimulus interval $(\mathrm{s})$ \\
\hline Phasic-tonic & $9-14$ & $100-120$ & 600 & 2 \\
Phasic & $11-18$ & $21-40$ & 600 & 2 \\
\hline
\end{tabular}

Table 2. Latency and duration of the auditory responses in the dorsal thalamus (diencephalon) and medial pallium (telencephalon) of the toad Bufo regularis $(n=10)$

\begin{tabular}{lcccc}
\hline & Latency $(\mathrm{ms})$ & Duration $(\mathrm{ms})$ & Stimulus $(\mathrm{Hz})$ & Stimulus interval $(\mathrm{s})$ \\
\hline Dorsal thalamus & $17-22$ & $40-100$ & 600 & 2 \\
Medial pallium & $36-42$ & $79-85$ & $600+1500$ & 10 \\
\hline
\end{tabular}




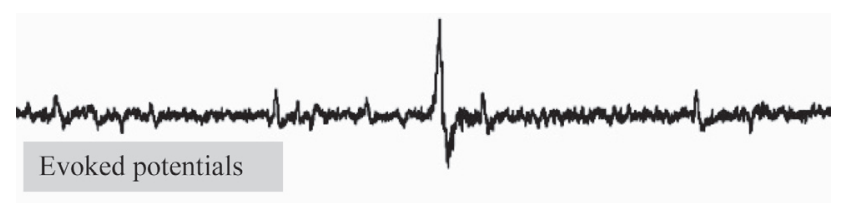

Sound stimulus

Figure 7. Evoked potentials response in the medial pallium of the toad Bufo regularis in response to a complex stimulus composed from the two main frequencies in the mating call of the toad $(600+1500 \mathrm{~Hz})$.

again to the baseline. The simple tones with a single carrier frequency failed to evoke any potential from this auditory nucleus. In contrast, the complex tones, which comprised the two main frequencies of the mating call of the toad Bufo regularis, were sufficient for evoking potentials from it. As shown in Table 2, the latencies of the responses ranged from 36 to $42 \mathrm{~ms}$ and the response duration ranged from 79 to $85 \mathrm{~ms}$ (10 animals).

\section{Discussion}

The small size and light weight of any device attached to an animal's head is obviously critical when the animal under investigation is small. For electrophysiological recordings in the awake animals, the use of small attachments also reduces the possibility that the animal removes or displaces them during the recording process. The microdrive, which was developed in the present study, has a length of $25 \mathrm{~mm}$ and total weight of $1.5 \mathrm{~g}$. These measures are very suitable to be carried by a small animal like a toad without making disturbances to their normal behaviour and movement.

A simple and rapid installation or removal of the microdrive is one of the major advantages that must be taken into consideration for constructing the microdrive (Korshunov 1995; Keating and Gerstein 2002). In the present design, the attachment and removal of the microdrive from the head of the animal was simple and easy.

One of the main challenges in recording from a freely moving animal is the capacity to easily change the position of the track of penetration in the brain. Several researchers have used different techniques to change the electrode trajectory in the brain of the animal under investigation. A swivelling guide tube held in a small, skull-mounted base by a low-melting-point metal alloy to adjust the trajectories of the microelectrode in the brain was designed (Malpeli
1992). Also, a design with eccentric electrode position which changed the penetration track many times in the same animal by placing the microdrive in the base at different orientations was used (Korshunov 1995). Recently, an implantable recording chamber for exchangeable electrode arrays has been designed (Galashan et al. 2011). This overcomes the problem that the probability to record single units or even small multiunit clusters decreases in chronic recordings. In comparison to the previous designs, the present design provides rather simplicity for multiple penetrations via the set screw, which is responsible for the up and down movements of the microelectrode holder. Furthermore, it allows the positioning of the microelectrode in the three dimensions. With the help of the base screw, the microelectrode can move in the dorso-ventral, anterio-posterior and medio-lateral directions. Several previously described drives are composed of a relatively large number of separate components to prevent electrode rotation during advancement in the brain tissue, many of which require fairly sophisticated machining (Bland et al. 1990; Malpeli et al. 1992; Korshunov 1995; Battaglia et al. 2009). In the present design, the movement of the driving screw is transferred firstly to the microelectrode holder and then to the microelectrode, in a manner that the microelectrode does not rotate or twist during the advancement and retraction movements. This offers an easy and simple design to minimize the tissue damage due to electrode rotation and hence obtain a relatively high quality of recording. It is also advantageous to choose readily available and economically safe materials to construct the microdrive. The present microdrive is made from plastic materials, which are available, inexpensive and very stable to be used several times in different experiments.

There are no data concerning the behavioural effectiveness of particular acoustic properties in the toad Bufo regularis. However, several investigators have assumed that each species-specific property is relevant to the conspecific animal (see review by Wilczynski and Ryan 2010). Therefore, the sound stimuli used in this study have been chosen to be simple and complex tone bursts, which have carrier frequencies similar to those extracted from the mating call of the toad Bufo regularis.

In the present study, multiunit recordings in the midbrain (torus semicircularis) were of phasic and phasic-tonic types. These results are in line with the previously reported results. In northen leopard frog (Ranapipiens), torus semicricularis units responses were divided into three major groups, phasic (19\%), phasic burst (10\%) and tonic (65\%) (Gooler and Feng 1992). Furthermore, two physiologically distinct classes of neurons in Rana pipiens, based on their response latencies and their selectivities to pulse repetition rates have been identified (Alder and Rose 2000). The torus semicircularis of anurans, homologue of the inferior colliculus in mammals, has been suggested to be not only a nucleus in the ascending 
auditory pathway, but also part of the audio-motor interface (Luksch and Walkowiak 1998; Hoke et al. 2007). Furthermore, the variety of inputs reaching the torus shows it to have different types of cells that respond differently to the acoustic stimulus (Endepols and Walkowiak 2001). In the present study the latencies were 11-18 ms and 9-14 ms for the phasic and phasic-tonic responses, respectively. A shift towards smaller latencies in the torus semicircularis in an immobilized preparation in comparison with recordings in anaesthetized animal was found (Epping and Eggermont 1986). Latencies between 19 to $21 \mathrm{~ms}$ have been obtained in the frog Discoglos suspictus by intracellular recordings in the midbrain nuclei using the isolated brain preparation technique (Luksch and Walkowiak 1998).

Evoked potentials in the dorsal thalamus (central nucleus) obtained in the present experiment are of bi-phasic pattern, starting with a large negative peak followed by a small positive overshoot which quickly returns to baseline. With respect to the wave morphology it should be noted that evoked potentials reflect global afferent activity and multiple generators may be involved in the production of a particular peak. The auditory pathway is not entirely serial; rather it is also organized in parallel and divergent fashion (Feng and Schellart 1999). Therefore, some pathways may become successively active in response to a single acoustic event. However, the morphological features of the evoked potentials obtained in this study match previously described evoked potentials in the thalamus of anurans (Hall and Feng 1987; Murdy and Capranica 1987). In the present study, the latency of the evoked potential responses in thalamus have a range of 17-22 ms. These results are in line with the reported evoked potentials in the thalamus (Hall and Feng 1987). The latter authors have reported that the latency of the acoustically evoked potentials recorded in the thalamus differ with the rise time of the presented stimuli and ranged from $27.2 \mathrm{~ms}$ (at $5 \mathrm{~ms}$ fall/rise time) to $46.4 \mathrm{~ms}$ (at $100 \mathrm{~ms}$ rise/fall time) in the same animal.

Evoked potentials in the present preparation were recorded in the medial pallium, one of the auditory sensitive areas in the telencephalon of the toad Bufo regularis. The response pattern was of bi-phasic type, starting with large a positive peak, followed by a small negative peak. The response latency ranged from $36-42 \mathrm{~ms}$, and response duration ranged from 79 to $85 \mathrm{~ms}$. Large positive potentials from the medial pallium of bullfrog have been recorded (Mudry and Capranica 1980). While simple acoustic stimuli failed to evoke responses in this region, complex tones with parameters similar to the natural species-specific vocalization were appropriate stimuli. In agreement with the aforementioned report, simple tones of single carrier frequency have failed to evoke pallial responses in this study, however, the sound stimuli which were composed of the two mating call dominant frequencies were able to evoke a large potential from this auditory center. This shows that the acoustic stimulus, which has parameters similar to the species-specific vocalization, is the most relevant sound used to evoke large responses from this species.

In conclusion, the microdrive developed in this study to record brain auditory evoked potentials and multiunit responses, is very suitable to be used with small animals like the Egyptian leopard toad Bufo regularis. This is also indicated by the reliable recordings from three auditory centres at three different levels (midbrain, diencephalon and telencephalon) and verified by the increase in latency of responses as the microelectrode was positioned rostrally along the auditory pathway.

Acknowledgement.The authors would like to thank DAAD for funding the stay of the first author in Germany. Special thank goes to Dr. Heike Endepols for her valuable comments and reviewing the manuscript. Thanks to Mrs Markus for helping in the preparations of the brain cross sections.

\section{References}

Akef M. S. A., Schneider H. (1990): Reproduction, calls and calling of the Leopard toad in Egypt (Anura: Bufonidae). Zool. Anz. 225, 123-132

Alder T. B., Rose G. J. (2000): Integration and recovery processes contribute to the temporal selectivity of neurons in the midbrain of the northen leopard frog, Rana pipiens. J. Comp. Physiol. A 186, 923-937

http://dx.doi.org/10.1007/s003590000144

Battaglia F. P., Kalenscher T., Cabral H., Winkel J., Bos J., Manuputy R., et al. (2009): The Lantern: An ultra-light micro-drive for multi-tetrode recordings in mice and other small animals. J. Neurosci. Methods 178, 291-300 http://dx.doi.org/10.1016/j.jneumeth.2008.12.024

Bland H. B., Colom L. V., Mani T. E. (1990): An improved version of a direct-drive, nonrotating manual microdrive. Brain Res. Bull. 25, 441-443 http://dx.doi.org/10.1016/0361-9230(90)90236-S

Carey B. M., Zelick R. (1993): The effect of sound level, temperature and dehydration on the brainstem auditory evoked potential in anuran amphibians. Hear. Res. 70, 216-228 http://dx.doi.org/10.1016/0378-5955(93)90160-3

Endepols H., Walkowiak W. (2001): Integration of ascending and descending inputs in the auditory midbrain of anurans. J. Comp. Physiol. A 186, 1119-1133 http://dx.doi.org/10.1007/s003590000159

Epping W. J. M., Eggermont J. J. (1986): Sensitivity of neurons in the auditory midbrain of the grassfrog to temporal characteristic of sound. I. Stimulation with acoustic clicks. Hear. Res. 24, 37-54 http://dx.doi.org/10.1016/0378-5955(86)90004-3

Feng A. S., Narins P. M., Xu C. H., Lin W. Y., Yu Z. L., Qiu Q., et al (2006). Ultrasonic communication in frogs. Nature 440, 333-336 http://dx.doi.org/10.1038/nature04416 
Feng A. S., Schellart N. A. M. (1999): Central auditory processing in fish and amphibians. In: Comparative Hearing: Fish and Amphibians. (Eds. R. R. Fay and A. N. Popper), pp. 218-268, Springer-Verlag, New York http://dx.doi.org/10.1007/978-1-4612-0533-3_6

Galashan F. O., Rempel H. C., Meyer A., Gruber-Dujardin E., Kreiter A. K., Wegener D. (2011): A new type of recording chamber with an easy-to-exchange microdrive array for chronic recordings in macaque monkeys. J. Neurophysiol. 5, 3092-3105 http://dx.doi.org/10.1152/jn.00508.2010

Gooler D. M., Feng A. S. (1992): Temporal coding in the frog auditory midbrain: the influence of duration and rise-fall time on the processing of complex amplitude-modulated stimuli. J. Neurophysiol. 67, 1-22

Hall J. C., Feng A. S. (1987): Evidence for parallel processing in the frog's auditory thalamus. J. Comp. Neurol. 258, 407-419 http://dx.doi.org/10.1002/cne.902580309

Hall J. C. (1994): Central processing of communication sounds in the anuran auditory system. Am. Zool. 34, 670-684

Hoke K. L., Ryan M. J., Wilczynski W. (2007): Integration of sensory and motor processing underlying social behaviour in túngara frogs. Proc. Biol. Sci. 274, 641-649 http://dx.doi.org/10.1098/rspb.2006.0038

Keating J. G., Gerstein G. L. (2002): A chronic multi-electrode microdrive for small animals. J. Neurosci. Methods 117, 201-206 http://dx.doi.org/10.1016/S0165-0270(02)00115-2

Korshunov V. A. (1995): Miniature microdrive for extracellular recording of neuronal activity in freely moving animals. J. Neurosci. Methods 57, 77-80 http://dx.doi.org/10.1016/0165-0270(94)00130-9

Kralik J. D., Dimitrov D. F., Krupa D. J., Katz D. B., Cohen D., Nicolelis M. A. (2001): Techniques for long-term multisite neuronal ensemble recordings in behaving animals. Methods 25, 121-150 http://dx.doi.org/10.1006/meth.2001.1231

Luksch H., Walkowiak W. (1998): Morphology and axonal projection patterns of auditory neurons in the midbrain of the painted frog, Discoglos suspictus. Hear. Res. 122, 1-17
http://dx.doi.org/10.1016/S0378-5955(98)00081-1

Malpeli J. G., Weyand T., LaClair R. A. (1992): New method of mounting and directing chronically implanted microdrives. J. Neurosci. Methods 44, 19-26 http://dx.doi.org/10.1016/0165-0270(92)90109-Q

McHugh T. J., Blum K. I., Tsien J. Z., Tonegawa S., Wilson M. A. (1996): Impaired hippocampal representation of space in CA1-specific NMDAR1 knockout mice. Cell 87, 1339-1349 http://dx.doi.org/10.1016/S0092-8674(00)81828-0

Mudry K. M., Capranica R. R. (1980): Evoked auditory activity within the telencephalon of the bullfrog (Ranacatesbeiana). Brain Res. 182, 303-311 http://dx.doi.org/10.1016/0006-8993(80)91190-7

Mudry K. M., Capranica R. R. (1987): Correlation between auditory thalamic area evoked responses and species-specific call characteristics. I. Ranacatesbeiana (Anura: Ranidae). J. Comp. Physiol. A 160, 477-489 http://dx.doi.org/10.1007/BF00615081

Neary T. J. (1988): Forebrain auditory pathways in ranid frogs. In: The Evolution of Amphibian Auditory System. (Eds. B. R. M. Fritzsch, W. Wilczynski, T. E. Hetherington and W. Walkowiak), pp. 233-252, Wiley, New York

Walkowiak W., Luksch H. (1994): Sensory motor interfacing in acoustic behavior of anurans. American Zoologist 34, 685-695

Wilczynski W., Ryan M. J. (2010): The behavioral neuroscience of anuran social signal processing. Curr. Opin. Neurobiol. 20, 754-763

http://dx.doi.org/10.1016/j.conb.2010.08.021

Yamamoto J., Wilson M. A. (2008): Large-scale chronically implantable precision motorized microdrive array for freely behaving animals. J. Neurophysiol. 4, 2430-2440 http://dx.doi.org/10.1152/jn.90687.2008

Yu A., Margoliash D. (1996): Temporal hierarchical control of singing in birds. Science 273, 1871-1875 http://dx.doi.org/10.1126/science.273.5283.1871

Received: September 22, 2012

Final version accepted: January 21, 2013 